\title{
Giono. La mémoire à l'œuvre, sous la direction de Jean-Yves Laurichesse et Sylvie Vignes
}

\section{Sara Arena}

\section{Q OpenEdition \\ 1 Journals}

\section{Edizione digitale}

URL: http://journals.openedition.org/studifrancesi/6090

DOI: 10.4000/studifrancesi.6090

ISSN: 2421-5856

\section{Editore}

Rosenberg \& Sellier

\section{Edizione cartacea}

Data di pubblicazione: 1 mai 2011

Paginazione: 210-211

ISSN: 0039-2944

\section{Notizia bibliografica digitale}

Sara Arena, "Giono. La mémoire à l'œuvre, sous la direction de Jean-Yves Laurichesse et Sylvie Vignes», Studi Francesi [Online], 163 (LV | I) | 2011, online dal 30 novembre 2015, consultato il 12 janvier 2021 URL: http://journals.openedition.org/studifrancesi/6090 ; DOI: https://doi.org/10.4000/studifrancesi. 6090

Questo documento è stato generato automaticamente il 12 janvier 2021.

\section{(c)}

Studi Francesi è distribuita con Licenza Creative Commons Attribuzione - Non commerciale - Non opere derivate 4.0 Internazionale. 


\title{
Giono. La mémoire à l'œuvre, sous la direction de Jean-Yves Laurichesse et Sylvie Vignes
}

\author{
Sara Arena
}

\section{NOTIZIA}

Giono. La mémoire à l'œeuvre, sous la direction de Jean Yves LAURICHESSE et Sylvie VIGNES, Toulouse, Presses Universitaires du Mirail, 2009 («Cribles»), pp. 345.

1 L'opera di Giono, pur contraddistinta, come precisano i curatori (Introduction, p. 11), da una forte componente immaginativa, più che autobiografica, e in cui la dimensione dell'istante appare per certi versi più sviluppata rispetto a quella del tempo passato, è indagata in questo volume collettaneo nella prospettiva particolare della memoria.

2 La prima parte del libro («Mémoire et vécu»), dedicata all'incidenza nel testo della storia individuale, è aperta dallo studio di Christian MORZEWSKI, che ricerca nell'infanzia dell'autore le radici di un motivo ricorrente nell'opera, quello del viaggio iniziatico (Un souvenir d'enfance de Jean Giono, pp.17-30). Da una prospettiva affine, Jacques LE GALL ricostruisce i rapporti di amicizia più importanti nella vita dell'autore, mettendone in luce alcuni echi testuali (Que sont mes amis devenus?, pp. 31-42), e Jean ARROUYE indaga la presenza, diretta e indiretta, dei ricordi della città d'origine nell'opera di Giono ( $L a$ Mémoire imaginative de Manosque, pp. 43-56). Similmente, Agnès CASTIGLIONE studia la trasposizione della morte della madre reale dell'autore in un testo di finzione ("Mort d'un personnage": la mémoire et la mère, pp. 83-96).

3 Altri contributi affrontano la questione della memoria individuale da una prospettiva tutta interna al testo. Marie-Anne ARNAUD-TOULOUSE (La Mémoire des objets, pp. 57-68) rileva il carico memoriale condensato attorno ad alcuni oggetti emblematici nell'opera, mentre Mireille SAсотTE indaga la stratificazione di diverse forme di memoria all'interno di un singolo romanzo («Mais où sont les neiges d'antan?» ou la mémoire à 
l'œuvre dans "Un de Baumugnes", pp. 69-82) e André-Alain MORELLo analizza la memoria individuale di un singolo personaggio (Dans la mémoire heureuse d'Angelo, pp. 97-110).

4 La pluralità delle forme di memoria coinvolte nella scrittura, tra cui anche la "memoria" intertestuale e quella intratestuale, è oggetto dello studio consacrato da Jacques MÉNY al romanzo incompiuto Dragoon ("Dragoon" ou le temps échappé, pp. 111-126). Jean-Yves LAURICHESSE affronta infine il tema della memoria a partire dal suo contraltare, l'oblio, presso sei personaggi (Un «petit bagage de loup». La mémoire et l'oubli chez quelques personnages de Giono, pp. 127-140).

Gli studi raccolti nella seconda sezione, «Mémoire, histoire, mythe», sono incentrati sulle tracce della storia collettiva e del mito. Una storia collettiva che può ritrovarsi anche trasfigurata nel testo attraverso il filtro dell'immaginario, come dimostra Laurent FOURCAUT, che mette in relazione la violenza della Prima guerra mondiale con l'immagine, ricorrente in Le Grand troupeau, di una madre divoratrice (Qu'est-ce qui se remémore dans "Le Grand troupeau"?, pp. 143-154). Anche il secondo conflitto mondiale trova eco in L'Eau vive e in alcuni testi successivi (Jean-Paul PILORGET, Mémoires de guerre. Le second conflit mondial dans la fiction gionienne, pp. 167-178).

Denis LABOURET contrappone al passato della storia il "passato di ricordi" (p. 179) che contraddistingue il genere testuale della "cronaca" declinato da Giono a partire dal 1946 ("Savoir vieillir»: la mémoire contre l'histoire dans les "Chroniques romanesques", pp.179-192), mentre Agnès LANDES rileva il collegamento esistente tra la disillusione generata dalla Seconda guerra mondiale e l'instaurarsi nella scrittura di Giono di una forma di nichilismo e di una crisi del rapporto col tempo (De la mort de l'Histoire au temps éclaté: nihilisme et post-modernité, pp. 193-206).

7 Si concentrano su alcune opere André ㅇ ("Le Moulin de Pologne", archéologie fictive d'une mémoire collective, pp. 207-220), che studia la posizione di archeologo-narratore assunta da Giono nel romanzo imperniato sulle gesta della famiglia dei Coste, e Patrick MAROT e Adeline NEDEY, che ricercano la presenza della tragedia e del mito in alcuni romanzi ("Intus et in cute». Mythe, tragédie et sens dans "Deux cavaliers de l'orage", "Un roi sans divertissement" et "Virgile" de Jean Giono, pp. 231-242). Ad antichissimi modelli mitologici, religiosi e letterari si raccorda il tema dei fratelli nemici, studiato da Jean BELLEMIN-NOËL (D’un hors-mémoire chez Giono, pp. 155-166).

8 Guri Ellen BARSTAD analizza alla luce del vissuto dell'autore la presenza di personaggi dall'appartenenza religiosa, cattolica e protestante (Des "bonnes sœurs" aux "darbistes": mémoire personnelle et sociale à l'œuvre, pp. 221-230), mentre Jacques СНАВОТ si concentra su una particolare dimensione della memoria, memoria abissale in cui, invece che ritrovarsi, l'uomo "si perde" (p. 244) (Mémoire de «la nuit des temps», pp. 243-253).

Oggetto della terza e ultima parte del libro, «Mémoire et stratégies d'écriture», sono invece le modalità della rappresentazione del ricordo e della memoria all'interno dei testi, come appare dall'analisi inaugurale di Sylvie vIGNES (Mémoire et nouvelle-instant: "Son dernier visage", pp. 257-268).

Julie MALlon (Ceux qui ont vu la chose ou les bifurcations de la mémoire, pp. 269-280) studia l'accostamento, alla memoria della voce narrante, di ulteriori voci che raccontano in prima persona, in un incastro di memorie destinato a incidere sul patto con il lettore. Similmente, è trasversale all'opera lo studio di Sébastien CAUQUIL, che ricostruisce la raffigurazione del ricordo nei testi (Jeux de mémoire: la mise en scène des souvenirs, pp. 293-306). 
11 Si concentrano su un solo romanzo Llewellyn BROWN, nell'intervento Mémoire et récit dans "L'Iris de Suse" (pp. 281-292) e Krzysztof JAROSZ (La mémoire autotextuelle dans "Noé", pp.319-329), che studia la creazione di un "idioletto intratestuale" (p.320), costruito attraverso una ripetizione di moduli ed espressioni volta a stimolare la memoria del lettore.

12 Béatrice воNномме mette infine in luce la presenza di echi, nell'opera in prosa, della produzione poetica di Giono, a sua volta innervata dalle letture, e dunque dalla memoria, di altri poeti (Mémoire poétique dans l'œuvre de Jean Giono, pp. 307-318). 